\title{
The follow-up care process in pediatric dentistry - part I
}

\author{
Mirel TOMA ${ }^{1}$, Florentina RADU ${ }^{2}$, Gabriel CIOCHINDA ${ }^{1}$, Cristina Nicoleta $\mathrm{MIHAI}^{1}$, \\ Sorin Nicolae POPESCU ${ }^{1}$, Viorel Stefan PERIEANU ${ }^{1}$, lleana IONESCU ${ }^{1}$, \\ Madalina Violeta PERIEANU ${ }^{1}$, Camelia IONESCU ${ }^{1}$, Gabriela IORGULESCU ${ }^{1}$, \\ Irina Adriana BEURAN ${ }^{1}$, Mihai BURLIBASA ${ }^{1}$, Oana-Cella ANDREI ${ }^{1}$, Liliana BURLIBASA ${ }^{3}$, \\ Corina Marilena CRISTACHE ${ }^{1}$, Mihai DAVID ${ }^{1}$, Silvia PER ${ }^{1}$ \\ 1"Carol Davila" University of Medicine and Pharmacy, Bucharest, Romania \\ ${ }^{2}$ Private dental practice, Bucharest, Romania \\ ${ }^{3}$ Faculty of Biology, University of Bucharest, Romania
}

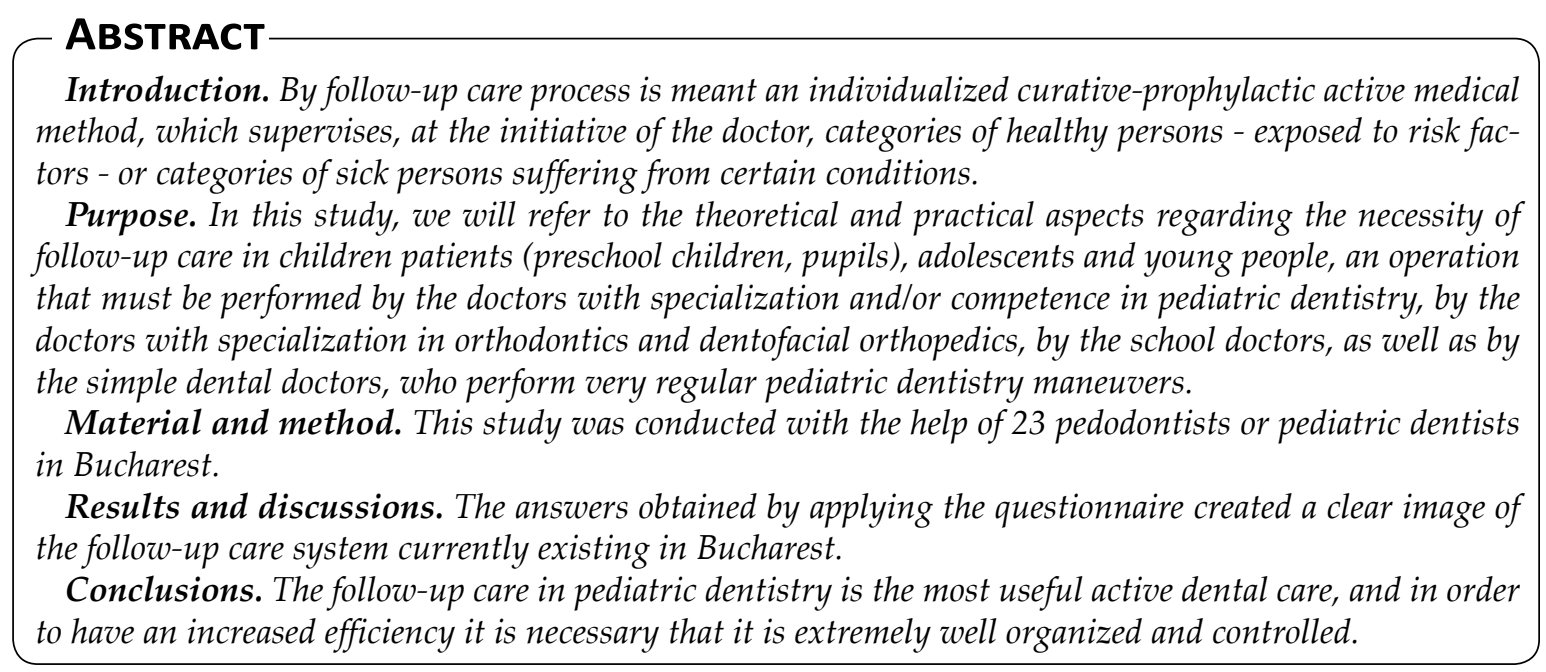

Keywords: follow-up care process, pediatric dentistry, temporary dentition, permanent dentition

\section{INTRODUCTION}

The follow-up care of the dental conditions is indicated by their presence in the majority of the individuals of our society, as well as by the important consequences that the respective diseases can have on the general state of health.
Specifically, when we talk about diseases with a wide spread, follow-up care can become a mass action, whose efficiency is related to all the individuals from one society (1-5).

We can say that follow-up care is a form of active assistance of an activity, and the efficiency of the dis- 
pensing actions is according to the capacity of covering all individuals, from the community in which this procedure is applied.

\section{PURPOSE}

Next, we will try to offer a more complex and complete definition to the follow-up care process with reference to pediatrics as a medical specialty, with implications especially in pediatric dentistry (1-5). Thus, we can specify that, follow-up care aims to prevent, fight and recover chronic diseases, through the organized medical supervision of certain categories of healthy or sick individuals and the application of corresponding medico-social measures. Practically, follow-up care is a method of prevention, control and recovery, being therefore a valuable tool for public health (1-5).

Follow-up care is a complex method of organizing the health care within the curative-prophylactic institutions, which provides for the active supervision of the health of certain groups of people, according to their physiological particularities (children of all ages, adolescents, pregnant women) and persons with certain conditions (gastric and duodenal ulcer, tuberculosis, cardiovascular diseases, oncological diseases, dermatological and venereal diseases, mental disorders, etc.) (1-5).

Usually, the follow-up care process is carried out by active and early diagnosis of chronic diseases or with potential for chronicity, by studying and eliminating the causes that contribute to their appearance and spread, as well as by taking certain social, curative-prophylactic and hygienic sanitary measures. At the same time, the follow-up care aims to maintain and strengthen the health of the population, to increase its longevity and quality of life, to study in depth the connection between the pathological changes that have occurred and the environment, especially the social factors (1-11).

The objectives of follow-up care can be systematized as follows (1-5):

- Creating of a database on chronic diseases in children included in communities (nurseries, kindergartens, schools, high schools, vocational schools, etc.);

- Observing how follow-up care is performed in school medical offices, including in school dental offices, with notification of any deficiencies;

- Optimizing the follow-up care and medical care in chronic diseases;

- Calculating the prevalence indices for the main categories of tracked chronic diseases, in order to describe the morbidity level through chronic diseases among children and young people in Romania.
Specifically, starting from the notions presented above, the objectives of this material are to particularize the follow-up care process in pediatric dentistry and to highlight and implement the necessity of follow-up care for pre-school patients, then continuing with school age, but also including adolescence, as well as and the age of youth. But, due to the space, we systematized the information into 2 distinct parts.

\section{MATERIAL AND METHOD}

As it is well known, the frequency of dental disorders, in an extremely high percentage at the age of the temporary dentition or the preschool age, as this age range is also known in the literature, it requires with extremely importance, if we take into account the effects of these conditions, the follow-up care process starting at this very age. This follow-up care process is extremely important starting right from the preschool age because, in our society, at this age of temporary dentition, children are included in extremely well-defined and expressed communities, such as nurseries and kindergartens.

But the age at which all the individuals of the respective society, without any exception, are included in a stable and very well-organized community for a duration of at least 9 years (the preparatory class, 4 primary school classes and 4 gymnasium school classes), is the school age, or the so-called school itself with the 9 compulsory classes before entering high school (before 1989, it was also called the general culture school) (1-11). Specifically, in the education in our country, the compulsory education of 9 classes (the preparatory class, 4 primary school classes and 4 secondary school classes), includes children between 5 and $14-15$ years (11-15).

From a dental point of view, the age between 6 years and 12 years, represents the most important age range, characterized by the coexistence of the temporary teeth in the process of resorption, with the most important permanent teeth (1-15).

But, it is extremely important the impressive frequency of dental caries and tooth and maxillary abnormalities that are installed or encountered at this age, whether we are talking about temporary dentition or we are talking about permanent dentition.

Both tooth decay and tooth and maxillary abnormalities untreated on time, can have particularly serious consequences and often irreversible repercussions over time both on the development of the dento-maxillary system and on the whole body.

But until the age of 25 years, the dento-maxillary system in continuous growth and normalization, presents a pathology with special consequences on the relationship between the constituent elements of the 
oral and dental system and on the health of the body (9-15).

We consider that, from the point of view of the dental interest, but also of the general medical interest, as well as of the organizational possibilities that could ensure the efficiency of the mass action, the dental follow-up care finds its most useful and indicated application at the school age (or so-called school, with the 9 compulsory classes before entering high school - the preparatory class, 4 primary school classes and 4 secondary school classes), it continues with the age of adolescence (high school, professional schools) and then with the age of youth, this the last age range being the period in which young people attend university and / or post-secondary courses. Basically, when discussing dental follow-up care in the aforementioned periods, it is necessary to mention in fact the characteristic follow-up care procedure that all professionals calls it as pediatric dentistry or pedodontics (115).

The process of follow-up care in pediatric dentistry, in the case of patients starting with the school age, then continuing with the age of adolescence and youth, is carried out in several stages, these being in absolute succession, the absence of a stage causing the follow-up care action to cease. These steps are as follows: screening, treatment (actual dental treatments), control and retreatment (1-15).

Starting from all these aspects mentioned above, in terms of the follow-up care process, we completed a questionnaire consisting of 6 questions, which was applied to a number of 23 dental practitioners, who practice pediatric dentistry (specialist and primary orthodontic doctors, specialist doctors and / or with pedodontic competence - pediatric dentistry, school doctors and / or simple dental practitioners, graduates of an authorized or recognized dental medicine faculty in Romania), which works in Bucharest. All the subjects work in the private dental offices and they are between 37 and 63 years old, being distributed as follows: 13 dental practitioners were female (56.52\%) and 10 dentists were male (43.48 \%) (Fig. 1).

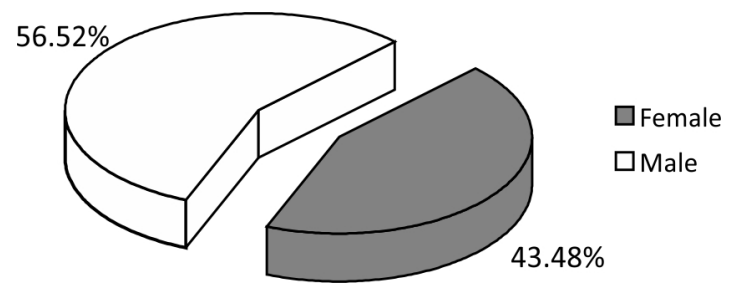

FIGURE 1. Gender distribution of dental practitioner involved in the study

Next, we will present the questionnaire applied to the 23 subjects:

\section{Questionnaire}

1. The follow-up care process is? a. A method of prevention, control and recovery, being a valuable tool for public health; $\boldsymbol{b}$. It is just a method of preventing health disorders; $c$. Is it just a method of recovery in the field of health. Correct answer: $\boldsymbol{a}$.

2. The follow-up care process is carried out? a. By active and early diagnosis of chronic or potential chronic diseases; $\boldsymbol{b}$. By studying and removing the causes that contribute to the occurrence and spread of chronic or potential chronic diseases; c. By taking certain social, curative-prophylactic and sanitary-hygienic measures, aiming to prevent chronic or potentially chronic diseases. Correct answers: $\boldsymbol{a}, \boldsymbol{b}, \boldsymbol{c}$.

3. The follow-up care process also aims at the following aspects? a. Maintaining and strengthening the health of the population; $\boldsymbol{b}$. Increasing the longevity and quality of life of the population; $c$. Deep study of the connection between the pathological changes that have occurred and the environment, especially the social factors. Correct answers: $\boldsymbol{a}, \boldsymbol{b}, \boldsymbol{c}$.

4. The objectives of the follow-up care process are as follows? a. To create a database on chronic diseases in children in communities; $\boldsymbol{b}$. Observation of the way in which the follow-up care is carried out in the school medical offices, including dental schools offices, with the detection of any deficiencies; c. Optimizing follow-up care and healthcare in chronic diseases; $d$. Calculation of prevalence indices for the main categories of chronic diseases included in follow-up care, in order to describe the situation of morbidity through chronic diseases among children and young people in the respective country. Correct answers: $\boldsymbol{a}, \boldsymbol{b}, \boldsymbol{c}, \boldsymbol{d}$.

5. From the point of view of pediatric dentistry, the follow-up care process finds its greatest utility in? a. School age and continues with the age of adolescence and youth; $\boldsymbol{b}$. At the age of the adult; $\boldsymbol{c}$. At elderly age. Correct answer: $a$.

6. The follow-up care process in the case of schoolage patients, and later in adolescence and youth, includes the following stages? a. Detection; $\boldsymbol{b}$. Involvement; $c$. Treatment (the actual dental treatments); $\boldsymbol{d}$. Conditioning; e. Control; f. Retreatment; g. Record. Correct answers are: $a, c, e, f$.

\section{RESULTS}

After analyzing the answers to the first question, we can conclude that only a small part of the respondents of this study (3 representing 13.04\%) did not understand what follow-up care process means (Fig. 2).

Regarding the way of conducting the follow-up care process, we find that most practitioners answered correctly (18 representing $78.26 \%$ ), namely all response variants. Only 5 practitioners (representing 
21.74\%) omitted the response variant related to the active and early diagnosis of chronic diseases (Fig. 3).

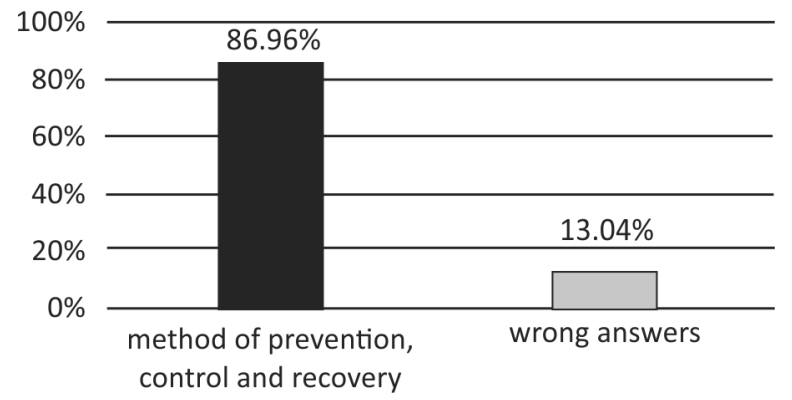

FIGURE 2. Understanding the concept of follow-up care

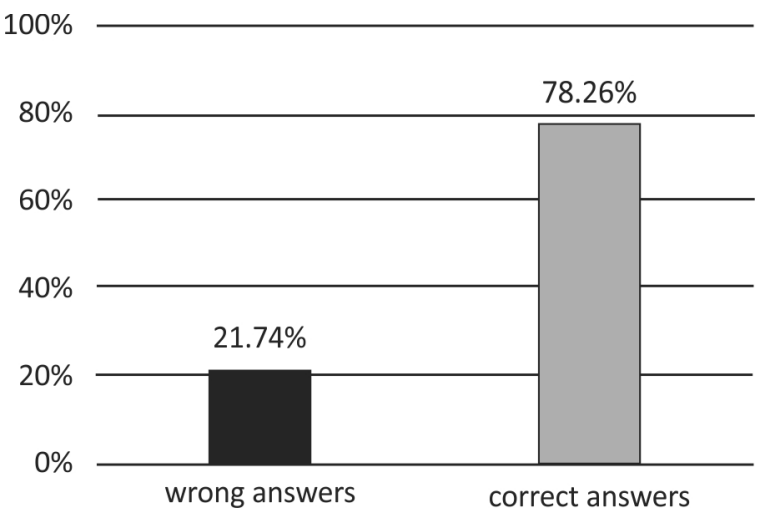

FIGURE 3. Methods of carrying out the follow-up care process

Regarding the secondary aspects covered by the follow-up care process, only a small part of the subjects included in the study ( 2 representing $8.70 \%$ ) responded incorrectly by omitting the answer related to studying the link between pathological changes and social factors (Fig. 4).

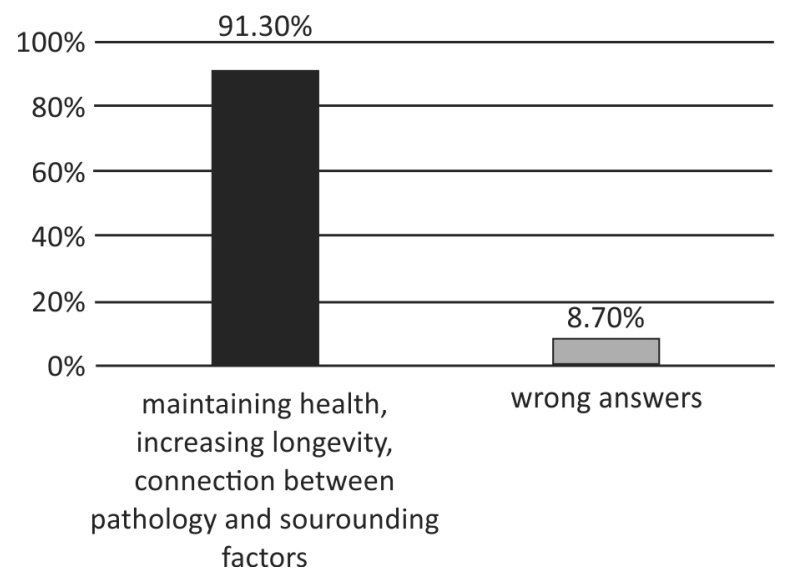

FIGURE 4. Secondary aspects of follow-up care process

One good thing is that all the doctors included in the study answered correctly the questions related to the most important aspects of follow-up care process, namely the goals and the age for which this process is very useful.

The last question of the study, regarding the stages of the follow-up care process, made the participants in the study a little difficult, so most practitioners (17, representing $73.91 \%$ ) answered correctly, and only a small part (6 practitioners, representing $26.09 \%$ ) have checked all the answer variants. As mentioned above, we can put the answers to this question on the age of some practitioners included in the study, the younger ones being more open to studying and updating their information in the field (Fig. 5).

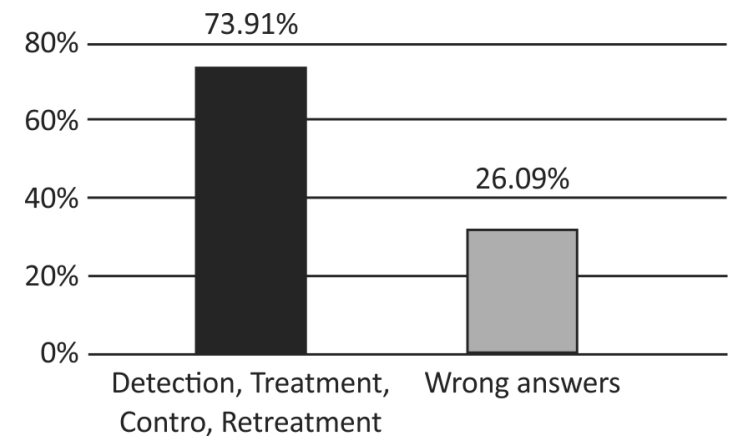

FIGURE 5. Knowledge of the steps that the follow-up care process is made of

\section{DISCUSSIONS}

All dental treatment schemes, regardless of the branch or age to which they are addressed, also included the follow-care part. Even if it is a secondary method of prevention, in addition to the actual treatment part, follow-up care plays an important role in preventing the appearance of carious lesions, a very important aspect especially in children.

The follow-up care process depends on both patients and medical staff. Patients should report for regular check-ups and treatment of new lesions. On the other hand, the medical staff must inform the patients about the importance of dental check-ups during the follow-up period, must know very well the dispensing process and adapt it according to each patient.

Most follow-up care programs provided a recall interval of approximately 6 months. However, depending on the region, education or national programs implemented, the range of dental checkups of patients varies. Berhan Nordin et al., in a survey from 2019, related to oral health of 11-12 year old indigenous children in Malaysia, based on a questionnaire applied to patients, found that $97.8 \%$ of the respondents perform a dental check-up once a year (16). Khanal et al., in 2014, a study of oral health practice among 12-15 year old children in Kathmandu noted that patients presented to the dentist only in cases of pain or the presence of stains in the teeth (17). Nazir MA, in a study from 2019 regarding: "Predictors of routine dental check-up among male adolescents in Saudi Arabia", observed that only $18.9 \%$ of study participants had routine dental visit within in the last year (18). 
In a 2008 study, Anthonappa et al. concluded that the six-month recall dental appointments for all children is not justified, being no support evidences either to justify or refute this time interval. The time interval must be customized by the dental practitioner according to the age of the child and the conditions he presents (19). In the same vein, Kärkkäinen et al., in a study of dental check-up intervals for adolescents in Finland, concluded that although the interval between follow-up visits increased, there was no increase in the frequency of caries (20).

At the level of professional organizations, multiple strategies have been developed and implemented to improve the oral health of patients, specific to each age group. Thus, the Romanian College of Dental Practitioners (Colegiul Medicilor Stomatologi din România) provides in the competencies of the dentist: "31. Establishment and implementation of complex follow-up care plans, applicable in school and pre-school communities" (5).

The American Academy of Pediatric Dentistry, in "Caries-risk assessment and management for infants, children, and adolescents", in Caries Management for children older than 6 years recommends:

- Recall every six to 12 months for children with low caries-risk;

- Recall every six months for children with moderate caries-risk;

- Recall every three months for children with high caries-risk (21);

The National Institute for Health and Care Excellence (UK), in "Dental checks: intervals between oral health reviews" from 2004, recommends that the patient should be assigned a recall interval of 3, 6, 9 or 12 months if the patient is younger than 18 years old. The recall interval should be reviewed again in the next appointment based on oral-health status, patient's response and health outcomes achieved (22).

Thus, the most important stage in the realization of the follow-up care process is represented by the knowledge and the correct application of this process by the doctor, which we wanted to evaluate at the level of the group included in the study.

\section{CONCLUSIONS}

After studying the answers, we can conclude several aspects, some extremely interesting.

About the follow-up care in pediatric dentistry (or pedodontics), it can be said that it represents the most useful active dental assistance.

To be truly effective, the follow-up care process specific to pediatric dentistry must be extremely well organized and controlled, while the medical personnel involved in the follow-up care processes, both the pediatric specialists and the auxiliary staff, must be very well trained, but also permanently guided and monitored.

When we talk about widespread dental conditions (dental caries, dento-maxillary anomalies), follow-up care becomes a mass action, whose efficiency is related to the whole society.

Practically, the follow-up care process in pediatric dentistry, has two well defined goals, namely:

- To ensure a harmonious development of the dento-maxillary system, which will contribute to the general health of the individual included in this follow-up care procedure;

- Ensure an efficient and broader coverage of all individuals in the community, and if not possible, of as many subjects as possible within that community.

The organization of these follow-up care actions is facilitated by the existence of stable communities, which can be tracked for much longer periods of time.

Most of the pedodontic practitioners (specialists in pediatric dentistry), over $70 \%$ of the subjects involved in the study, have shown a very good training, in terms of knowledge and learning of the notions, which aim to carry out consistent actions of follow-up care in well-defined and established communities.

\section{Acknowledgement}

In this article, all the authors have equal contribution with the first author.

Conflict of interest: none declared Financial support: none declared

\section{REFERENCES}

1. Gall I. Asistența stomatologică. Editura Didactică și Pedagogică, București, 1971.

2. Miyasaki-Ching CM. Elemente clinice de stomatologie. Editura All Educațional, București, 2001.

3. Zarnea L. Pedodonție. Editura Didactică și Pedagogică, București, 1993.

4. Burlibașa M, Bilinschi LG, Pavăl B et al. Preliminary study regarding the necessity of dispensing in the dental medical assistance of pupils, teenagers and young patients. Acta Medica Transilvanica. 2018;23(1):9698.

5. Colegiul Medicilor Dentiști din Romania. Decizie nr. 49 din 30 iunie 2012. Portal Legislativ. [Online] 2012. [Cited: 02 18, 2020.] http://legislatie.just.ro/Public/ DetaliiDocument/139632.
6. Foley J.I. Management of carious primary molar teeth by UK postgraduates in paediatric dentistry. Eur Arch Paediatr Dent. 2010;11:294-7.

7. Ahmed H.M. Pulpectomy procedures in primary molar teeth. Eur J Gen Dent 2014;3:3-10.

8. Jamieson LM, Smithers LG, Hedges $\mathrm{J}$ et al. Follow-up of an Intervention to Reduce 
Dental Caries in Indigenous Australian Children: A Secondary Analysis of a Randomized Clinical Trial. JAMA Netw Open. 2019;2(3):e190648.

9. Luca R. Pedodonție (Vol. I). Editura Cermaprint, București, 2003.

10. Luca R. Pedodonție (Vol. II). Editura Cermaprint, București, 2003

11. Luca R. Pedodonție (Vol. III). Editura Cermaprint, Bucuresti, 2013.

12. Bodnar DC, Burlibașa L, Vârlan C et al. Mercury, biocompatibility and its impact on environment. Metalurgia International. 2009;14:95-100.

13. Burlibașa $M$, Tănase $G$, Muntianu $L$ et al. Quality of life, a multidisciplinary concept with economic and social impacts in medical practice. Metalurgia International. 2010;15(4):88-90.

14. Mocuț D, Popovici IA, Burlibașa L et al. Impact of the living conditions on population health. Metalurgia International. 2009;14:17-19.
15. Ionescu CA, Popovici LR, Mocuța D et al. The quality of human life from the perspective of sustainable development Metalurgia International. 2009;14:41-43.

16. Berhan Nordin EA, Shoaib LA, Mohd Yusof ZY, Manan NM, Othman SA. Oral health-related quality of life among 11-12 year old indigenous children in Malaysia. BMC Oral Health. 2019;19(1):152.

17. Khanal S, Acharya J. Dental caries status and oral health practice among 12-15 year old children in Jorpati, Kathmandu. Nepal Med Coll J. 2014;16(1):84-87.

18. Nazir MA. Predictors of Routine Dental Check-up Among Male Adolescents in Saudi Arabia. Acta Stomatol Croat. 2019;53(3):255-263.

19. Anthonappa RP, King NM. Six-month recall dental appointments, for all children, are (un)justifiable. J Clin Pediatr Dent. 2008;33(1):1-8.
20. Kärkkäinen S, Seppä L, Hausen H. Dental check-up intervals and caries preventive measures received by adolescents in Finland. Community Dent Health. 2001;18(3):157-161.

21. The American Academy of Pediatric Dentistry. Best Practices: Caries-risk assessment and management. The American Academy of Pediatric Dentistry, . [Online] 2019. [Cited: 02 18, 2020.] https:// www.aapd.org/media/Policies_Guidelines/ BP_CariesRiskAssessment.pdf.

22. National Institute for Health and Care Excellence. Dental checks: interval between oral health reviews. National Institute for Health and Care Excellence, . [Online] 2004. [Cited: 02 19, 2020.] https:// www.nice.org.uk/guidance/cg19/resources/ dental-checks-intervals-between-oralhealth-reviews-pdf- 975274023877 . 